\title{
A New Impact Simulation Device for Testing Passive Safety Equipment
}

\author{
J. Hampl \\ Passive Safety Department of DEKRA Automobil a.s., Prague, Czech Republic
}

DOI: $10.2478 / v 10158-012-0008-1$

\begin{abstract}
The described device presents a cheap improved system for routine impact tests. The impacts are simulated by cart accelerations. The necessary energy is accumulated in rubber ropes. The required shape of acceleration curve is achieved with replaceable cams. The reactive acceleration force moves the drive system in the opposite direction on the base, which is shaped as an inverted box. Its walls are sealed in contact with the floor. The inner space of the "box" is empty. Therefore, the total "weight" increases. The recoil is limited by springs and hydraulic shock absorbers. For easy replacement of the device in the test room area the lifting function of the exhauster and several small wheels with level adjustment can be used.
\end{abstract}

KEY WORDS: Passive safety of vehicles; replacing impact deceleration by acceleration; energy accumulation in elastic ropes.

\section{INTRODUCTION}

Within the state-aided project "Passive Safety of Children in Cars" a great dispersion of the shapes of deceleration curves was observed (these decelerations simulate vehicle crashes). This hindered finding an optimal method of routine testing side impacts of child restraint systems, for example. To solve this problem we have designed the device described below.

\section{EXISTING DEVICES FOR SIMULATING VEHICLE IMPACTS}

A usual method of how to simulate impact deceleration, i.e. a steep slowing down of the tested object, is the sharp stopping of a sled or trolley carrying the tested object, such as a dummy with fastened seat belt. Using this method child restraint systems, competition car seats, partition walls separating passengers from the cargo space, and so on, can also be tested. The required deceleration rates attain values corresponding to up to ten times the acceleration of gravity and the tested object's speed is expressed in tens of kilometers, and the braking distance in decimeters.

\subsection{Current State of Simulating Impacts}

The most conventional breaking system uses a resilient bush made of plastics with reversible deformation properties, inserted in a steel tube and furnished with a hole the diameter of which is smaller than the diameter of a pin. The pin is connected to the tested object 
and is protruding into the bush during the impacting process. The kinetic energy of the moved object is thus absorbed by the friction between the surface of the pin and the internal surface of the bush hole. The required rate and diagram of deceleration during intrusion of the pin into the bush is achieved by providing variable diameters of the bush hole. Such a breaking device is presumed to be used, for example, pursuant to UNECE Regulations No. 16 and 44 (although other methods with the same effect are not excluded).

Nevertheless, it may be understood that even upon the maintenance of the prescribed bush temperature, the actual pin deceleration value will fluctuate due to the age and history of the bush when exposed to tens of repeated tests. Therefore, the above-mentioned standards allow for relatively broad limits, in which the diagram of deceleration is defined. For example, with UNECE Regulation No. 44, the limit for the maximum deceleration is 20 - 28 g. This may lead to disputable statements as to the compliance with the prescribed standards.

Concerning the physical effects, the impact deceleration may be substituted by impact acceleration exhibiting the same time behavior. To this effect, various devices, also called catapults, have been used. For example, UNECE Regulation No. 44, Series of Amendments No. 04 (§ 8.1.3.12.1.3.2 and Annex 7, Appendices 1 a 2) states the use of a catapulting device.

Hydraulic driven catapults simulating the course of impacter acceleration through the precise and prompt control of the flow rate of the fluid moving at a high speed through the hydraulic system are also known. Such systems are able to simulate various rates and diagrams of acceleration, which, due to a feedback system, may be maintained within relatively close limits. Such highly flexible and sophisticated systems are, however, very expensive and therefore more suitable for research and development purposes than for the routine practice of testing laboratories and shops.

\section{PRINCIPLE OF THE NEW IMPACT SIMULATOR (catapult with elastic ropes)}

The tested object is placed on a trolley whose movement is guided by a slide bar during the impact simulation. The trolley receives the acceleration impulse from the actuatorbumper which has a cylindrical roller bearing on the opposite end. The bearing is in contact with a cam which is shaped in such a way so that the required acceleration course is attained. The cam is fixed on a common shaft with a winch for a steel cable attached to the elastic ropes bundle. During the impact the energy accumulated in it passes to the accelerating trolley. After having reached the required velocity the trolley equipped with wheels leaves the guiding bars defining the section measured. Immediately, intensive deceleration is initiated using guy ropes being unreeled from intensely braked winches. The stopping distance is short (ca $2 \mathrm{~m}$ ). After unhitching the guy ropes the trolley can be pushed away and another one with a further object installed for testing can be attached.

For stopping the movement of the actuator a spring and a hydraulic shock absorber are used. Similarly, the rotation of the winch and cam is stopped. To elongate the elastic ropes an electromotor is used.

That catapult is not fixed to the test room floor; it stands freely on it. But it is not the impact simulator itself which is in contact with the floor; a separated base shaped like an empty inverted box stands under it. The base is sealed on its edges so that the underpressure generated by an exhauster heightens the force pressing the catapult to the floor. During the impact the simulator moves by reaction along the base in the opposite direction to the trolley (similar to that of the cannon recoil). The recoil length is limited by springs and shock absorbers.

The device is made up of a minimum number of components, which may guarantee maximum reliability and the minimum of trouble-causing incidents. Its operation is simple 
and enables the selection and performance of the desired or required course of acceleration consistent with the requirements of the standards by selecting a suitable shape of the cam. As compared with a hydraulic controlled catapult, the production cost of the device is considerably lower, which in turn may result in low operating costs.

\subsection{DESCRIPTION OF THE NEW IMPACT SIMULATOR}

The text and the mechanical scheme of the catapult itself (without the base and without the recoil system) is taken from the patent application PCT/EP/2008/064326. Note: In the previous paragraph (2) the tested object is situated on a trolley, while in the following description (used for the patent application) the tested object is mounted on a sled sliding on rails. Such a difference is immaterial.

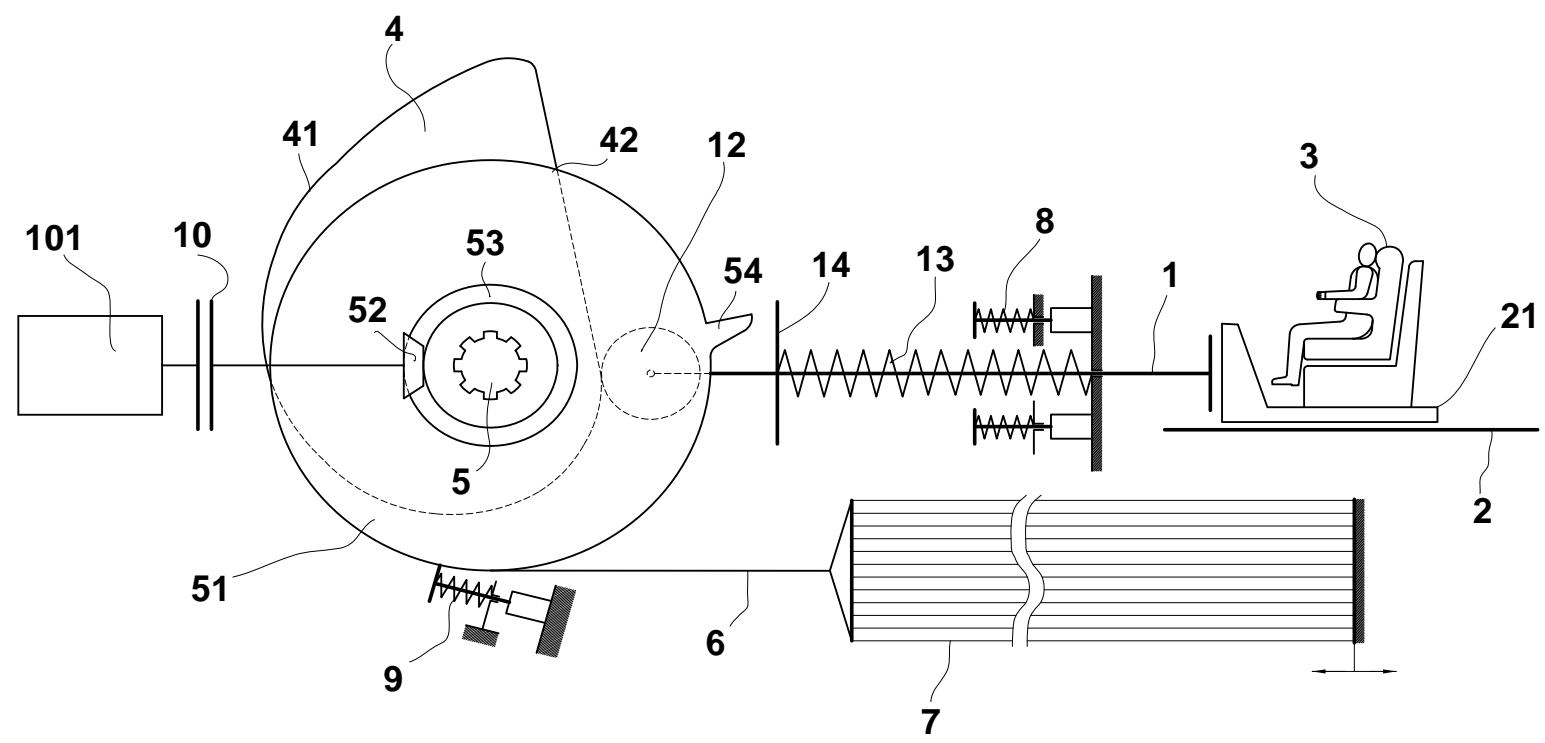

Figure 1: Mechanical schema of the catapult.

As an example of a testing device for dynamic tests simulating impact into the front part of a vehicle a catapult was selected with which a child restraint system with a dummy was installed. The tested object was situated in a forward direction. This arrangement is consistent with Paragraph 7.1.4.4.1.1. of ECE Regulation No. 44-04. The basic calculation was made in order to verify the feasibility of the device. More specifically, the calculation was made in order to determine the shape of the cam used for a simulation of this type of impact.

In the figure above, the child restraint system 3 with a child dummy is placed on a sled 21. The sled 21 can move on rails 2 and can be equipped with wheels for moving in the testing area in order to reduce friction. This part of the device, i.e. the sled system, is shown only to understand better the purpose of the invention. It is demonstrated on a smaller scale.

To simulate a crash deceleration the impacter 1 pushes the sled 21 with the tested object. The impacter is fitted at its other end with a roller 12 with antifriction bearings. The roller 12 of the impacter 1 is pushed to the cam 4 by a spring 13 over a spring disc 14 . The cam 4 is mounted on a fluted shaft 5 and its outer periphery is composed of an active surface portion 41 and a transitory surface portion 42 . The active surface portion 41 is formed in such a shape that upon rotation of the cam 4 the required and predetermined course of acceleration of the impacter 1 derived from rolling the roller 12 along the active surface 41 of the cam 4 is achieved. 
For various types of acceleration diagrams a number of cams 4 with appropriately shaped active surfaces corresponding to desired acceleration diagram types may be mounted on the fluted shaft 4 and then adjusted into a position in contact with the roller 12 . The shaft 5 further bears a rope winch 51 to which a pull rope 6 is firmly attached. The opposite end of the pull rope 6 is attached to an energy source - in this case to a linear engine in the form of an elastic ropes bundle 7 .

To stop the impacter 1 at the end of its movement before the roller 12 reaches the transitory surface portion 42 of the cam 4 the first shock absorber assembly 8 is mounted on the immovable part of the testing device structure. To stop the delayed rotation of the rope winch 51 and that of the cam 4 before the roller 12 engages the opposite end of the transitory surface portion 42, the rope winch 51 is provided with a side stop 54 for engagement with the second shock absorber assembly 9 also mounted on the immovable part of the testing device structure.

The shaft 5 bearing the rope winch 51 is driven through a clutch 10, pinion 52, and crown gear 53 assembly by an external motor 101. By winding up the pull rope 6 on the rope winch 51 , the elastic rope bundle 7 is stretched and linear motor loaded with energy. The anchored end of the elastic ropes bundle 7 is mounted for longitudinal motion on the immobile testing device structure in the direction of the pull rope 6, more specifically in the direction of the force exerted by the elastic ropes bundle 7. This arrangement enables the setting of the maximum extension of the elastic ropes bundle 7 by election of the corresponding position of the anchored end of the bundle, and thus to adjust the energy capacity of the linear motor and finally the speed of the sled 21.

\section{INFORMATION ABOUT THE PRELIMINARY COMPUTATION METHOD FOR THE CAM OF THE IMPACT SIMULATOR}

The dynamics of the system are described by balancing the actuating force with the inertial force of the sled:

Actuating force minus inertial force of the cam, winch and ropes minus transmission ratio multiplied by inertial force of the sled and actuator equals 0

$\mathrm{F}_{\text {elastic ropes }}-\mathrm{m}_{\text {cam+winch+ropes }} * \mathrm{a}_{\text {elastic ropes }}-\mathrm{i} *(\mathrm{~m} * \mathrm{a})_{\text {sled+actuator }}=0$

where $m_{\text {cam+winch+ropes }}$ incorporates inertia torque of the cam and winch

For reasons of simpler computation a linear dependence of the elastic force on the elongation of the ropes is supposed:

$\mathrm{F}=\mathrm{F}_{\max }-\mathrm{Z} * \mathrm{k}$

$\mathbf{Z}$ is replacement of the moving end of the elastic ropes [m]

$\mathbf{k}$ is rigidity modulus of the elastic ropes bundle $[\mathrm{N} / \mathrm{m}]$

When (2) is substituted into (1), then:

$\mathrm{F}_{\max }-\mathrm{Z} * \mathrm{k}-\mathrm{m}_{\text {cam+winch+ropes }} * \mathrm{a}_{\text {elastic ropes }}-\mathrm{i} * \mathrm{~m}_{\text {sled+actuator }} * \mathrm{a}_{\text {sled+actuator }}=0$

so the notation of transmission course:

$\mathrm{i}=\mathrm{F}_{\max }-\mathrm{Z} * \mathrm{k}-\mathrm{m}_{\text {cam+winch+ropes }} * \mathrm{a}_{\text {elastic ropes }} / \mathrm{m}_{\text {sled+actuator }} * \mathrm{a}_{\text {sled+actuator }}$

( $\mathrm{Z}=\Sigma \mathrm{z}$, where $\mathrm{z}=\mathrm{i} *\left[\mathrm{~s}_{\mathrm{n}}-\mathrm{s}_{\mathrm{n}-1}\right] ; \quad \mathrm{s}$ the relevant distance of the trolley) 
The computation is not trivial, not only due to the relevant length of the necessary releasing of the elastic ropes $\mathrm{Z}$, but also the deceleration of the moving end of the elastic ropes bundle depends on the transmission ratio. This means that the input value is influenced by the computation result, and cyclic dependence (feedback) occurs. Therefore the iterative computation is necessary.

Owing to reduced cam steepness at the initial impact it is useful to defer starting deceleration of the trolley (therefore the elastic energy is first used for accelerating the cam and the winch, and only later for the trolley acceleration).

The preliminary computation includes neither the friction, nor the non-linear course of the elastic ropes force (see the following diagram relating to the rope diameter $20 \mathrm{~mm}$; the producer Sandow Technic recommends using it in an elongation range of $20-80 \%$ ). Additionally the contact kinematics between the cam and bearing of the actuator were not taken into account (the cylindrical roller bearing was replaced with an edge).

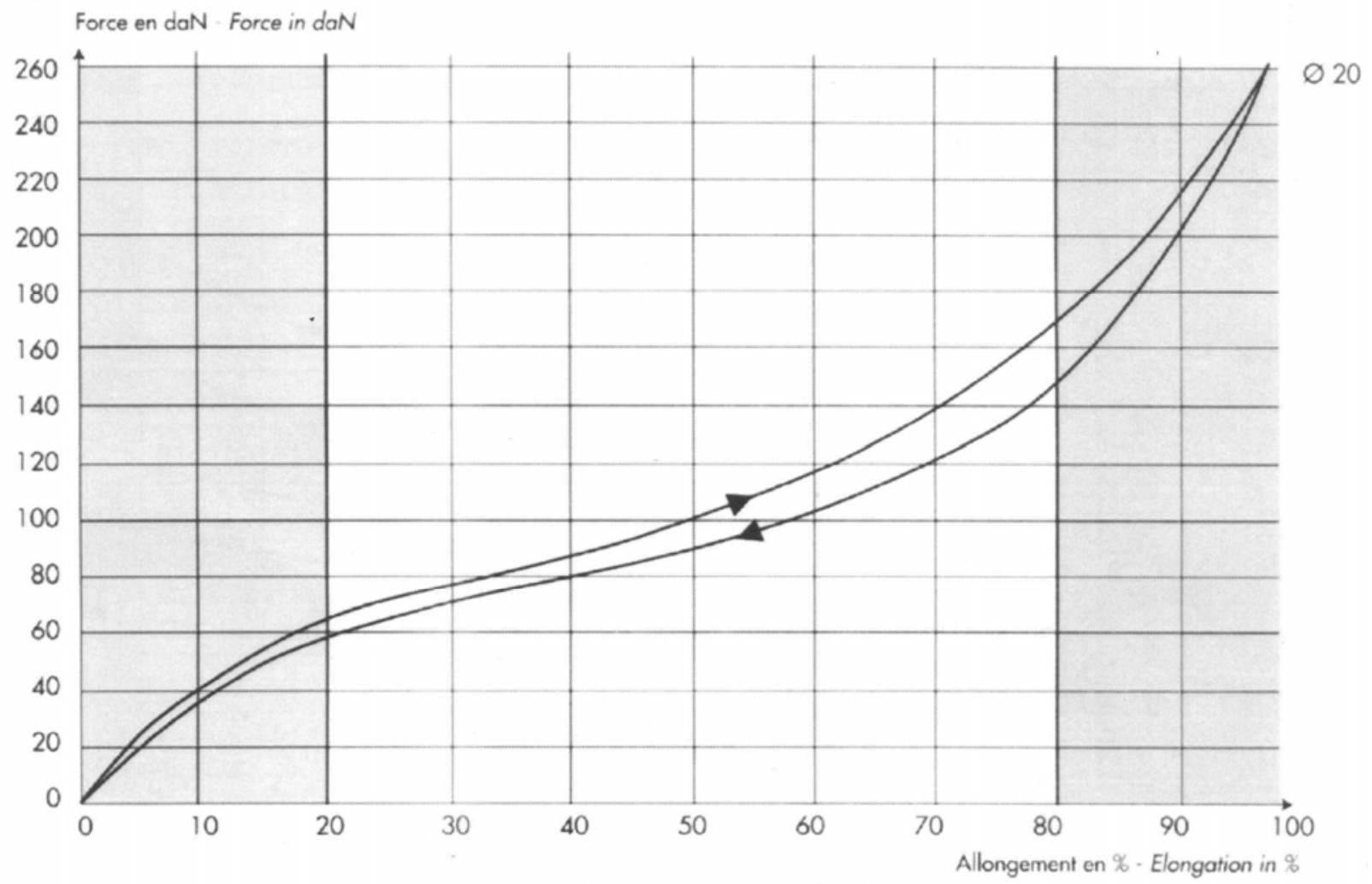

Figure 2: Relation between the force and the elongation of the rubber rope $\varnothing 20 \mathrm{~mm}$.

The calculation of the cam shape was used for impact simulation according to UNECE Regulation No. 44, § 8.1.3.1.1.3.2, which specifies the dynamic testing of the child restraint system by frontal impact. In the next diagram the trolley acceleration is limited from above by the red broken line and from below by the blue broken line. Moreover, the acceleration curve has to lie above the green straight line segment. According to ISO 17373 Standard the beginning of the impact is defined by an acceleration value of $0.5 \mathrm{~g}$. The final speed is $52 \mathrm{~km} / \mathrm{h}+0-2 \mathrm{~km} / \mathrm{h}$. The accelerating distance is $650 \pm 50 \mathrm{~mm}$. 
To find an approximate cam shape the acceleration course was designed using two slightly different sinusoidal curves joined in their peaks (see the violet curve in the next diagram).

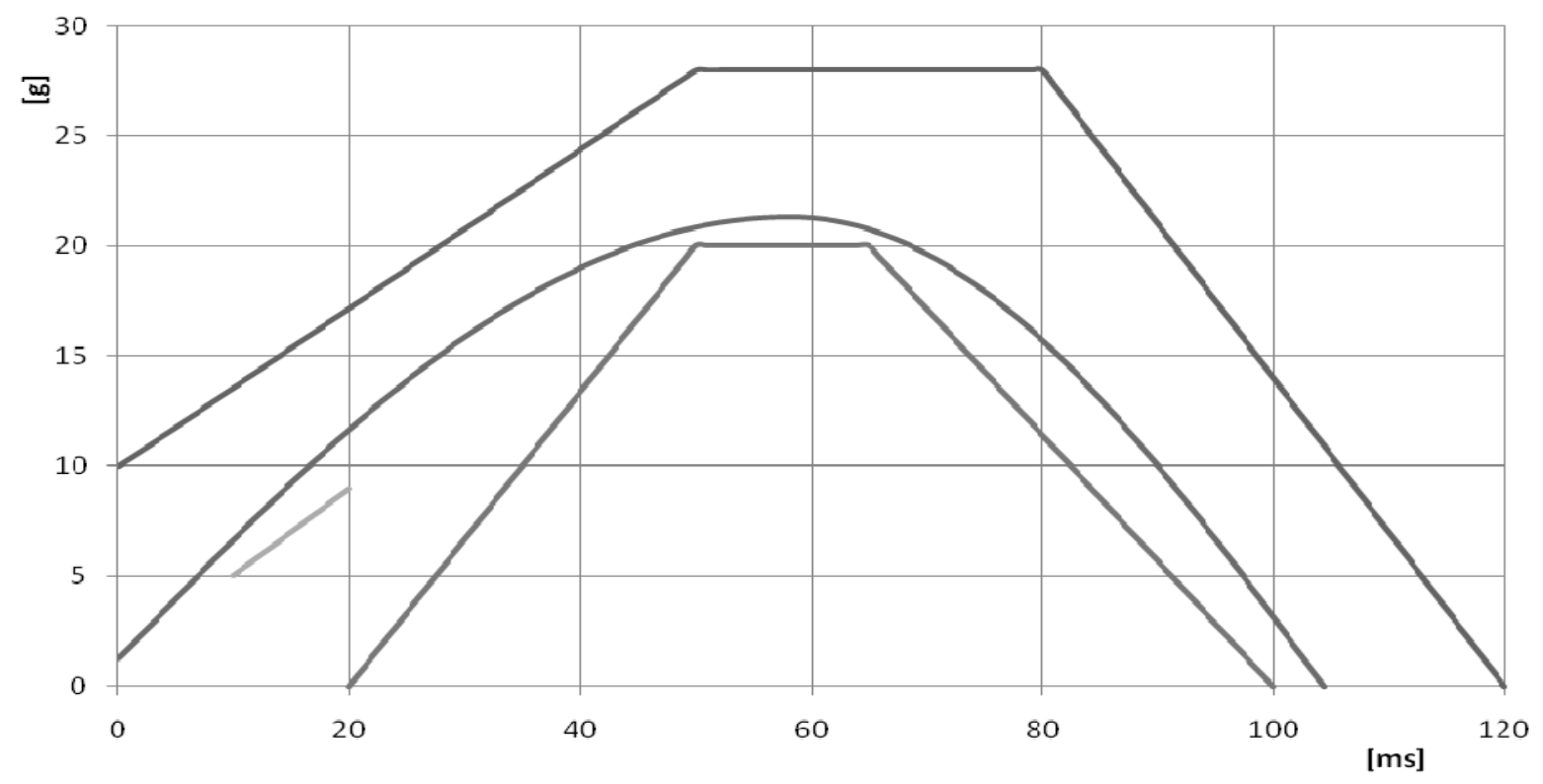

Figure 3: The designed acceleration curve within the limits of § 8.1.3.1.1.3.2 R44-04 UNECE.

In the following diagram the speed course (red curve ) was gained by integrating the acceleration from the previous diagram. The integration of the speed course resulted in the blue curve (track dependence on time). Time [ms] is on the horizontal axis. The scale on the vertical axis applies to acceleration [g] (black curve), speed $[\mathrm{km} / \mathrm{h}$ ] and accelerating distance [cm]. The designed acceleration course more or less met the above mentioned requirements. It will be upgraded within the detailed computation taking into account all the influences which were ignored during the preliminary calculation.

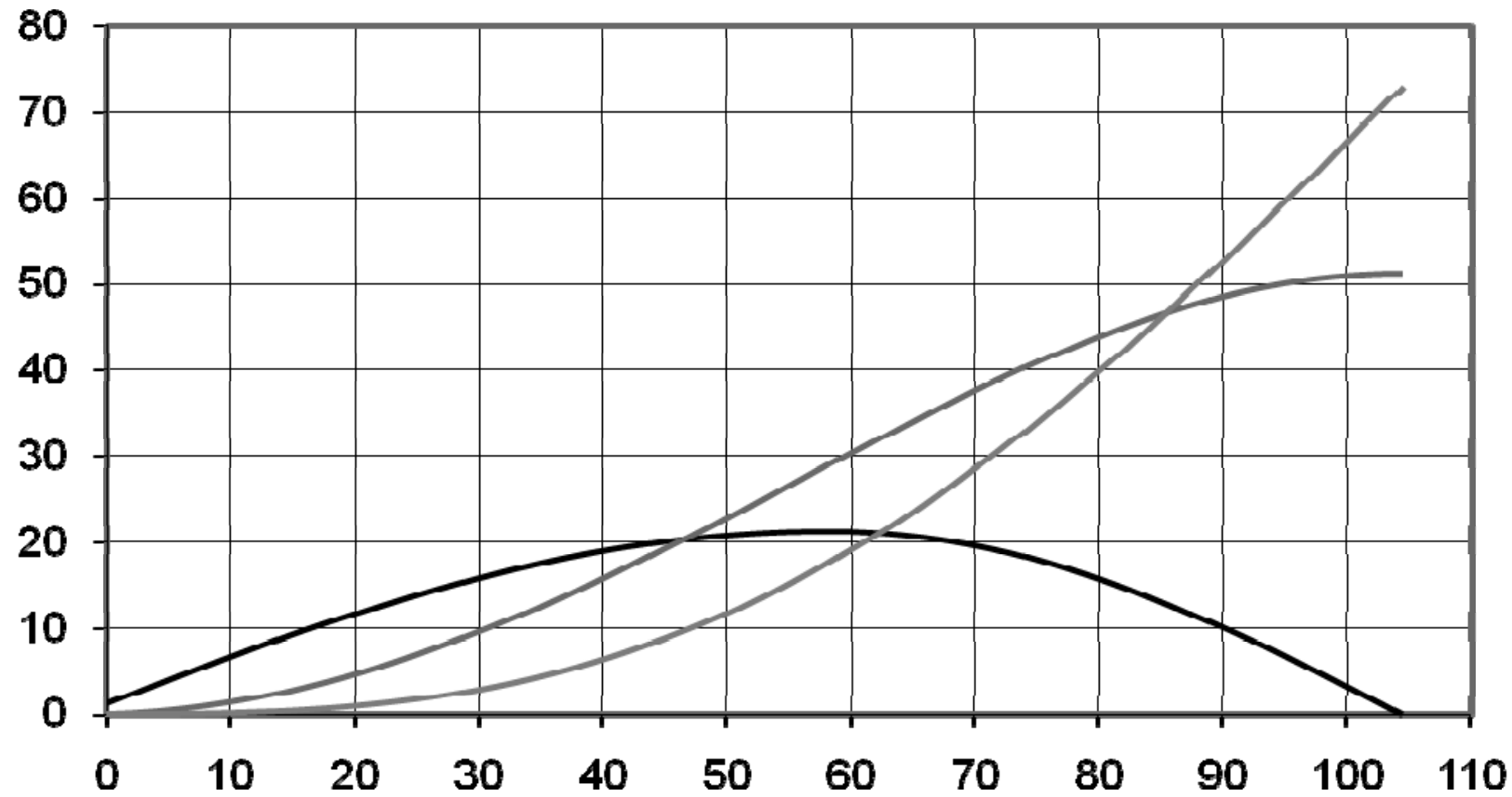

Figure 4: Courses of speed and accelerating distance for the designed acceleration course. 
The informative shape of the active part of the cam (next fig.) was formed on the basis of preliminary calculation of the transmission ratio between the motions of the trolley and elastic ropes bundle. The cam's eccentricity depends on its rotation (after transfer into polar coordinates).

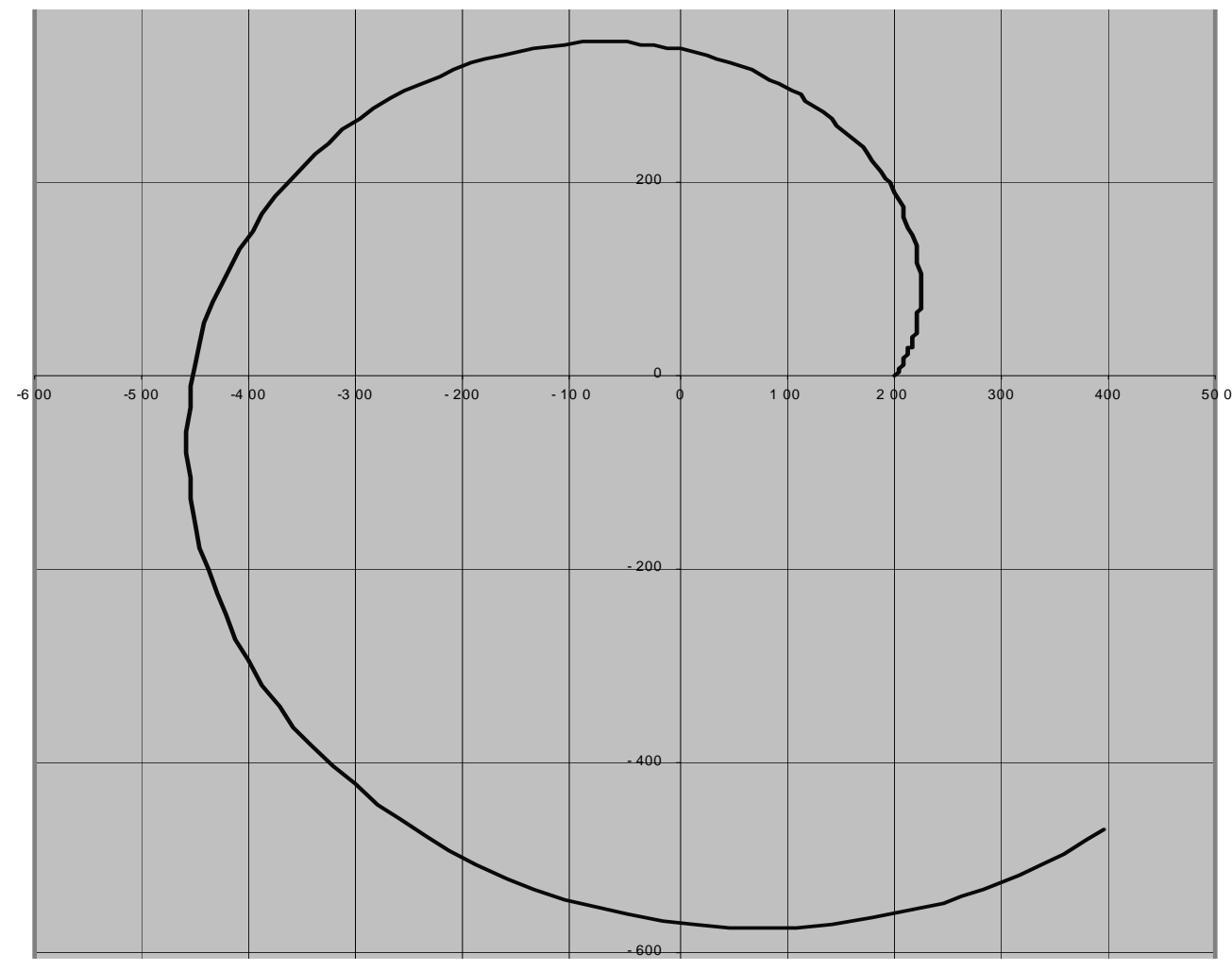

Figure 5: Shape of active part of the cam.

\section{EXPECTED ADVANTAGES OF THE NEW IMPACT SIMULATOR}

- Simulation of the required deceleration curve shape of the impact is more accurate than at the device using braking polyurethane tubes.

- The relatively expensive braking polyurethane tubes are not needed.

- When the impact starts, the tested object (e.g. dummy in a restraint system) is in the specified position, and not in a position somehow moved by the acceleration force during the trolley's initial acceleration.

- If the safety belt ruptures in the present testing device, the dummy will continue moving and can be damaged; while in the accelerating simulator the dummy remains in place.

- The trolley of the present devices is substituted by a simple sled gliding on the track without generating parasitic oscillation (unlike the restless rolling wheels of the trolley).

- The stopping distance after impact can be considerably shorter than the moving-off distance of the decelerating simulator as the change of the dummy's position through intensive braking after impact is irrelevant. Therefore the necessary space in the test room can be significantly smaller. For transporting the complete device a platform semitrailer can be used.

- The braking part of the sled track can be bifurcated so that more sleds can be used. Productivity will thereby increase. 
- Due to a low acquisition price smaller manufacturers of restraint systems will also be able to acquire these simulators for internal production checking. Therefore, batch production will further decrease the price.

\section{INDUSTRIAL APPLICABILITY}

The device can be used by testing shops performing dynamic tests of safety systems to satisfy the standard requirements of regulatory authorities. Additionally, it may be used by the testing laboratories of manufacturers producing safety systems to control their current production and, subject to minor modification to the device, even for research and development purposes.

\section{ACKNOWLEDGEMENTS}

The article was prepared under the terms of the project "Passive Safety of Children in Cars" (No. CG711-040-160) which has been supported by the Ministry of Transport of the Czech Republic.

\section{REFERENCES}

Gehre, C. et al., 2008. Restrained Children in Side Impacts - Crash Tests and Simulation. In 1st Conference Protection of Children in Cars, Cologne, 2003.

Gallegos, D. et al., 2008. Frontal Absorbed Energy Systems Applied to a CRS. In Protection of Children in Cars. International Conference Proceedings, Munich.

Hampl, J. et al., 2008. Pasivní bezpečnost dětí v motorových vozidlech. DEKRA Automobil Report of the project CG711-040-160 for the Czech Transport Ministry, pp. 48 - 52. (inCzech).

Instron ${ }^{\circledR}$ Structural Testing Systems (IST) [online]. (C) 2010 Illinois Tool Works Inc. Retrieved from: www.instron.com/ist.

Messring [online]. (c) 2011 MESSRING Systembau MSG GmbH. Retrieved from: www.messring.de/wp-content/uploads/MESSRING_Accelerator-Sled-Systems.pdf

UNEC E: Paragraph 8.1.3.1.1.3.2, Regulation No. 44 - 04. 